\title{
CLC-3 and SOX2 regulate the cell cycle in DU145 cells
}

\author{
JIAHONG CHEN $^{1 *}$, FANG WANG $^{1 *}$, YULI LU $^{2}$, SHANGQI YANG $^{2}$, \\ XUEQIN CHEN $^{1}$, YOUWEI HUANG ${ }^{3}$ and XI LIN ${ }^{1,4}$
}

\author{
Departments of ${ }^{1}$ Pharmacology, ${ }^{2}$ Epidemiology and Health Statistics, and ${ }^{3}$ Pathology and Pathophysiology, \\ School of Medicine; ${ }^{4}$ Key Laboratory for Environmental Exposure and Health, Environment College, \\ Jinan University, Guangzhou, Guangdong 510632, P.R. China
}

Received October 4, 2019; Accepted July 23, 2020

DOI: $10.3892 / \mathrm{ol} .2020 .12235$

\begin{abstract}
Sex determining region Y-box 2 (SOX2) is a transcription factor that serves a role in numerous different types of malignant cancer. Altered expression of chloride channel proteins has been described in a variety of malignancies. However, the association between SOX2 and chloride channel proteins is not yet fully understood. The present study investigated the association between SOX2 and chloride voltage-gated channel 3 (CLC-3) in prostate cancer. Flow cytometry demonstrated that the inactivation of CLC-3 or SOX2 arrested cell cycle progression in the $\mathrm{G}_{0} / \mathrm{G}_{1}$ phase. Furthermore, CLC-3 was observed to bind to SOX2, and vice versa, by co-immunoprecipitation. SOX2 appears to initiate and maintain prostate cancer tumorigenesis, in part, by modulating the cell cycle. These findings indicate the potential of SOX 2 and CLC- 3 as targets for the development of multi-targeted therapeutics.
\end{abstract}

\section{Introduction}

Prostate cancer is a prevalent type of cancer in older men and is one of the leading causes of cancer-associated mortality among men worldwide (1). Hormone therapy, or androgen ablation therapy, is considered the first-line clinical treatment for patients with metastatic disease; however, in the majority of cases, the effect of androgen deprivation is temporary (2). Subsequently, these patients ultimately become insensitive to androgen ablation, and hormone-refractory prostate cancer (HRPC) develops after 18-24 months of conventional treatment (3). HRPC is a common type of malignant, metastatic tumor with poor prognosis, common recurrence and a high

Correspondence to: Professor Xi Lin, Department of Pharmacology, School of Medicine, Jinan University, 601 Huangpu Avenue West, Guangzhou, Guangdong 510632, P.R. China

E-mail: linx_jnu@163.com

*Contributed equally

Key words: sex determining region Y-box 2, chloride voltage-gated channel 3, cell cycle, DU145 fatality rate (4). Therefore, the inevitable progression of HRPC presents the urgent need for novel therapeutic approaches (5).

The cancer stem cell theory proposes that tumor tissue harbors its own cancer stem cells and regards these cells as the key to regeneration, metastasis and recurrence (6). A number of reports have demonstrated that tumor malignancy and oncogenesis are associated with the expression of stemness genes, such as sex determining region Y-box 2 (SOX2), OCT-4, Kruppel like factor 4 and c-Myc $(7,8)$. Malignant tumors are associated with characteristics of tumor-like stem cells (9). The high expression of stemness proteins causes malignant tumor cells to be insensitive to drugs and enhances drug resistance (10). Resistant malignant cancers exhibit abnormal expression of stemness genes, which are capable of inducing self-renewal and differentiation programs (11). The expression of stemness genes is closely associated with cancer stem cell resistance $(12,13)$. The transcription factor SOX2, a stem-like cell marker is associated with the expression of numerous gene products involved in cell proliferation, growth, differentiation and apoptosis (14). SOX2 maintains the self-renewal activity of undifferentiated embryonic stem cells and is expressed abnormally in a variety of tumors (15). In squamous cell carcinoma, SOX2 serves an important role in regulating tumor growth and maintaining stem cell qualities (16). SOX2 can improve the self-renewal ability of lung cancer stem cells, which upregulate SOX2 (17). Furthermore, in neuroblastoma stem cells, SOX2 promotes biological processes, such as proliferation, clonal formation and tumorigenesis, and exerts an inhibitory effect on differentiation (18). Downregulation of SOX2 can arrest the cell cycle and promote apoptosis to inhibit the growth of gastric cancer cells (19). Therefore, identifying the key regulatory targets for stemness genes should be a key focus for future research in order to decrease cancer stem cell resistance.

Chloride voltage-gated channels (CLCs) form permeable cell membrane channels for chloride ions or other anions and can be classified into seven subtypes: CLC-1, CLC-2, CLC-3, CLC-4, CLC-5, CLC-6 and CLC-7 (20). CLC expression has a direct influence on the proliferation, migration and cell cycle of cancer cells (21). CLC-1 regulates the metastasis and invasion of gastric cancer cells (22), and CLC-3 is relevant to the proliferation of the nasopharyngeal carcinoma CNE-2Z cell line (23). CLC-3 affects the cell cycle by altering the expression levels of cyclin D1, which, in turn, regulates CLC-3 via CDK4/6 phosphorylation (24). However, CLC proteins are both 
ion transport channels and signaling proteins in vivo $(25,26)$. The present study demonstrated that CLCs serve important roles in cell proliferation, cell cycle and apoptosis. It was hypothesized that CLCs are also involved in regulating stemness genes, and the results may provide novel insights into identifying therapeutic targets.

The present study aimed to investigate the ability of the CLC inhibitor DIDS to inhibit the cell cycle, and to investigate the associations between CLC-3 and SOX2 in the HRPC DU145 cell line. The effects of CLC-3- and SOX2-knockdown on cell cycle progression, and the associations between CLC-3 and SOX2 were observed. In addition, the present study aimed to identify potential targets for HRPC therapy from the perspective of CLC proteins and SOX2.

\section{Materials and methods}

Cell culture. The DU145 and PC-3 cell lines were purchased from the Shanghai Institute of Biochemistry. HFF-1 was purchased from the American Type Culture Collection. DU145 and HFF-1 cells were maintained in DMEM (Thermo Fisher Scientific, Inc.) and PC-3 cells were maintained in RPMI 1640 (Thermo Fisher Scientific, Inc.). The media were supplemented with 10\% FBS (Thermo Fisher Scientific, Inc.) and $1 \%$ penicillin/streptomycin (Thermo Fisher Scientific, Inc.) in a $5 \% \mathrm{CO}_{2}$ incubator at $37^{\circ} \mathrm{C}$.

Cell viability assays. For MTT assays, 5,000 cells/well were seeded in 96-well culture plates, incubated for $24 \mathrm{~h}$ and treated with $0,25,50,100,200$ or $400 \mu \mathrm{M}$ CLC inhibitor DIDS. After $48 \mathrm{~h}$, the cells were incubated with $0.5 \mathrm{mg} / \mathrm{ml}$ MTT and the plates were cultured for $4 \mathrm{~h}$ at $37^{\circ} \mathrm{C}$. The culture medium was removed and formazan crystals were dissolved in $100 \mu \mathrm{l}$ DMSO. The absorbance of each well was determined at $490 \mathrm{~nm}$ using an iMark microplate reader (Bio-Rad Laboratories, Inc.). Each condition was evaluated in six wells, and all experiments were repeated at least three times.

Flow cytometry. Cell apoptosis was analyzed using an Annexin V/PI kit (BD Biosciences) and flow cytometry. DU145 cells were collected by trypsinization, washed twice in PBS, fixed with $500 \mu \mathrm{l}$ binding buffer, and incubated with $5 \mu \mathrm{l}$ Annexin V-EGFP and the DNA binding dye PI $(50 \mathrm{mg} / \mathrm{ml})$ for $5-15 \mathrm{~min}$ at $37^{\circ} \mathrm{C}$ in the dark. Finally, the cells were analyzed using an Elite flow cytometer (CytoFLEX S; Beckman Coulter, Inc.) with a peak fluorescence gate to distinguish aggregates after $1 \mathrm{~h}$. Next, the cell cycle distribution was assessed. Briefly, following treatment with $100 \mu \mathrm{M}$ DIDS for $48 \mathrm{~h}$, the cells were collected by trypsinization, washed in PBS and fixed in $70 \%$ ethanol for $30 \mathrm{~min}$ at $4^{\circ} \mathrm{C}$. After being washed with PBS, the cells were incubated with PI $(50 \mathrm{mg} / \mathrm{ml})$ and RNase $(1.0 \mathrm{mg} / \mathrm{ml})$ for $30 \mathrm{~min}$ at $37^{\circ} \mathrm{C}$ in the dark. Finally, the cells were washed, and red fluorescence was analyzed using an Elite flow cytometer (CytoFLEX S, Beckman Coulter, Inc.) with a peak fluorescence gate to distinguish aggregates. All data were analyzed by ModFit LT 4.1 (Verity Software House, Inc.).

Reverse transcription-quantitative PCR. Total RNA in DU145 cells was extracted using TRIzol ${ }^{\circledR}$ reagent (Thermo
Fisher Scientific, Inc.) and reverse transcribed to cDNA using oligo(dT), reverse transcriptase, $5 \mathrm{X}$ reaction buffer and dNTPs (all Thermo Fisher Scientific, Inc.). cDNA and oligo(dT) were incubated at $65^{\circ} \mathrm{C}$ for $5 \mathrm{~min}$ and then reverse transcriptase, $5 \mathrm{X}$ reaction buffer and dNTPs were added and incubated for $60 \mathrm{~min}$ at $42^{\circ} \mathrm{C}$. The reaction was terminated by heating at $70^{\circ} \mathrm{C}$ for $10 \mathrm{~min}$. Relative gene expression was analyzed using the $2^{-\Delta \Delta \mathrm{Cq}}$ method (27) with GAPDH as the internal control gene, and was quantified using SuperReal PreMix SYBR Green (FP204-02; Tiangen Biotech Co., Ltd.) on an Applied Biosystems 7500 Fast Real-Time PCR system (Thermo Fisher Scientific, Inc.). The thermocycling conditions were as follows: Initial denaturation at $95^{\circ} \mathrm{C}$ for $5 \mathrm{~min}$, followed by 40 cycles at $95^{\circ} \mathrm{C}$ for $30 \mathrm{sec}, 58^{\circ} \mathrm{C}$ for $30 \mathrm{sec}$ and $72^{\circ} \mathrm{C}$ for $40 \mathrm{sec}$, then a final extension at $72^{\circ} \mathrm{C}$ for $10 \mathrm{~min}$. The gene-specific primer pairs were as follows: CLC-1 forward, 5'-CAGCATCTGTGC C-3' and reverse, 5'-GTGCTTAGCAAGAAACTGGC-3'; CLC-2 forward, 5'-AGACAATCCCTACACCCTTCAA-3' and reverse, 5'-TGTCGGTAGAACACCTTGTCAC-3'; CLC-3 forward, 5'-CAAUGGAUUUCCUGUCAUATT-3' and reverse, 5'-UAUGACAGGAAAUCCAUUGTA-3; CLC-4 forward, 5'-GCGTCTCATCGGGTTTGC-3' and reverse, 5'-TTGCTC ACAATGCCCTCTTTG-3'; CLC-5 forward, 5'-CTGTGC CACTGCTTCAAC-3' and reverse, 5'-CTGAGGGCAAAT CCCACTAA-3'; CLC-6 forward, 5'-GTCGCGCAAGACTGT AACCA-3' and reverse, 5'-CGGCGAAATTCCATACCTG-3'; CLC-7 forward, 5'-GAAAGGAAGGGCCAATGATC-3' and reverse, 5'-CAGGAACTGATYCCAGAAGG-3'; and GAPDH forward, 5'-CTCATGACCACAGTCCATGC-3' and reverse, 5'-CACATTGGGGGTAGGAACAC-3'.

Antibodies and western blotting. The cells were lysed in M-PER mammalian protein extraction reagent (Thermo Fisher Scientific, Inc.), Protein concentrations were measured using a BCA protein assay kit (Pierce; Thermo Fisher Scientific, Inc.). Equal amounts $(10 \mu \mathrm{g})$ of protein were resolved by $10 \%$ SDS-PAGE and transferred to a PVDF membrane (Merck KGaA). After blocking with 5\% skimmed dried milk at room temperature for $1 \mathrm{~h}$, the PVDF membrane was probed with the indicated primary antibody at $4^{\circ} \mathrm{C}$ overnight. The following antibodies were used in the present study: Tubulin (1:10,000; cat. no. T5168; Sigma-Aldrich; Merck KGaA), CLC-3 (1:1,000; cat. no. ab28736; Abcam), cyclin D1 (1:1,000; cat. no. 2922; Cell Signaling Technology, Inc.), P27 (1:1,000; cat. no. 3686; Cell Signaling Technology, Inc.) and SOX2 (1:1,000; cat. no. 3579; Cell Signaling Technology, Inc.). The next day, the PVDF membrane was blocked with HRP-conjugated secondary antibody (goat anti-rabbit; cat. no. ARG65351; or goat anti-mouse; cat. no. ARG65350; 1:5,000; Arigo Biolaboratories Corp.) at room temperature for $1 \mathrm{~h}$ and then results were detected by electrochemiluminescence using Immobilon Western Chemiluminescent HRP Substrate (cat. no. WBKLS0500; Merck Millipore). ImageJ software (v.1.48; National Institutes of Health) was used to semi-quantify the bands.

Cell transfection. CLC-3 and SOX2 small interfering RNAs (siRNAs) were purchased from Guangzhou RiboBio Co., Ltd. The siRNA target sequences $\left(5^{\prime}-3^{\prime}\right)$ were as follows: siCLC-3-\#1, CGACGCAAGTCCACGAAAT; siCLC-3-\#2, 
GCAGGCATTGGAGTATATT; siCLC-3-\#3, CAATAG AAAGTGCCAGGAA; siSOX2-\#1, CCAAGACGCTCA TGAAGAA; siSOX2-\#2, CCACCTACAGCATGTCCTA; and siSOX2-\#3, GCTCGCAGACCTACATGAA. Cells were incubated with RPMI 1640 containing 2.5\% FBS (without penicillin/streptomycin). siRNAs $(25 \mathrm{nM})$ were transfected using Lipofectamine RNAiMAX (13778-150; Thermo Fisher Scientific, Inc.) with OPTI-MEM (31985070; Thermo Fisher Scientific, Inc.) for $24 \mathrm{~h}$. All experiments were performed according to the manufacturers' protocols.

Immunofluorescence staining. A total of $1 \times 10^{5}$ cells/well were seeded in 6-well culture plates and exposed to different treatments. After fixing with $4 \%(\mathrm{v} / \mathrm{v})$ paraformaldehyde in room temperature for $30 \mathrm{~min}$, they were permeabilized with $0.1 \%(\mathrm{v} / \mathrm{v})$ Triton X-100/PBS and blocked with 5\% (v/v) BSA (Guangzhou Weijia Technology Co., Ltd.) or PBS for $10 \mathrm{~min}$. Primary antibodies (SOX2; cat. no. 3579; dilution, 1:500 in 0.1\% Triton X-100; Cell Signaling Technology, Inc.) were used and the cells placed in a wet box at $4^{\circ} \mathrm{C}$ overnight. Secondary antibodies (cat. no. 31460; FITC-conjugated goat anti-rabbit IgG; dilution, 1:150 in PBS; Thermo Fisher Scientific, Inc.) were used and placed in a wet box at room temperature for $1 \mathrm{~h}$ to detect and visualize SOX2. Hoechst 33342 (DAPI; Molecular Probes; Thermo Fisher Scientific, Inc.) was used to label DNA. Images were captured using fluorescence microscopy (Olympus Corporation).

Coimmunoprecipitation. Cells were collected by trypsinization, washed three times with PBS, and lysed in $400 \mu \mathrm{l}$ NETN lysis buffer [100 mM NaCl, $0.5 \mathrm{mM}$ EDTA, $20 \mathrm{mM}$ Tris-Cl (pH 8.0) and 0.5\% (v/v) nonidet P-40] for 20 min. Protein A/G beads (C600694; Sangon Biotech Co., Ltd.) that had been washed in ice-cold PBS were mixed with the target antibody and cell lysates under rotation for $2-4 \mathrm{~h}$ at $4^{\circ} \mathrm{C}$. The mixture was centrifuged at $4,000 \mathrm{x}$ g for $1 \mathrm{~min}$ at $4^{\circ} \mathrm{C}$, exposed to a protease inhibitor and PMSF for $24 \mathrm{~h}$, and washed with NETN2. Western blotting, performed as aforementioned, was used to detect the presence of specific proteins: SOX2 (cat. no. 3579; Cell Signaling Technology, Inc.) or CLC-3 (cat. no. ab28736; Abcam).

Gene chip technology. Total RNA was extracted using TRIzol reagent (Thermo Fisher Scientific, Inc.) and further purified using a Qiagen RNeasy Mini kit (74106) according to the manufacturer's protocol. RNA quality was assessed by $1 \%$ formaldehyde agarose gel electrophoresis and quantitated spectrophotometrically. For the microarray analysis, $0.1 \mu \mathrm{g}$ total RNA was used to synthesize double-stranded, biotin-tagged cDNA using a MessageAmp ${ }^{\mathrm{TM}}$ Premier RNA Amplification kit (cat. no. 4385821; Thermo Fisher Scientific, Inc.) according to the manufacturers' protocols. The resulting biotin-tagged cRNA was fragmented to 35-200 bases according to the Affymetrix protocols. Hybridization was performed at $45^{\circ} \mathrm{C}$ with rotation for $16 \mathrm{~h}$ (Affymetrix Gene Chip Hybridization Oven 640; Thermo Fisher Scientific, Inc.). The Gene Chip arrays were washed, stained (streptavidin-phycoerythrin) on an Affymetrix Fluidics Station 450 (Thermo Fisher Scientific, Inc.) and scanned on a Gene Chip Scanner 3000 (Thermo Fisher Scientific, Inc.).
Normalization. The hybridization data were analyzed using Gene Chip Operating software (GCOS v 1.4; Thermo Fisher Scientific, Inc.). The scanned images were first assessed visually and subsequently analyzed to generate raw data files (CEL files) using the default settings in GCOS 1.4. An invariant set normalization procedure was performed to normalize the different arrays using a DNA-chip analyzer (dChip).

Analysis of two factors. In a comparison analysis, the present study applied a two-class unpaired method in the Significant Analysis of Microarray software (v.4.01; Standford University.) to identify significantly differentially expressed genes between the test and control groups. Stemness-associated genes were determined to be significantly differentially expressed with a selection threshold of false discovery rate (FDR) $<5 \%$ and fold-change $>2.0$ in the SAM output.

Tissue specificity analysis. Microarray data were preliminarily screened with a selection threshold of FDR $<5 \%$ using a multiclass method in SAM. The resulting data were then screened for a $>2$-fold-change in expression in the tissue of interest compared with other tissues and a Wilcoxon Rank-Sum test significance level of $0.05(\mathrm{P}<0.05)$.

In vivo studies. Mice were purchased from Beijing Vital River Laboratory Animal Technology Co., Ltd. The resuspension solution of DU145 cancer cells $\left(3 \times 10^{6}\right.$ cells/mouse) in PBS was inoculated subcutaneously into the hind-flank of 4-week-old male BALB/c-nu/nu mice weighing 18-20 g. A total of 20 mice were used. Animals were housed at $26^{\circ} \mathrm{C}$, with a relative humidity of $50-60 \%$ and a room wind speed of 0.1-0.2 m/sec. Fresh air was used for ventilation at a frequency of 15 times/ $h$ in a barrier environment. The animal room used fluorescent light, with a 12-h light and 12-h dark cycle. The animals were allowed free intake of water and food. Tumors developed after 1 week, and the mice were randomly divided into three groups. The treatment group was intravenously injected with $45 \mathrm{mg} / \mathrm{kg}$ DIDS (D3514-250 MG; Sigma-Aldrich; Merck KGaA) in a total volume of $100 \mu$ l. Intraperitoneal injection with DMSO in a total volume of $100 \mu 1(1.3$ or $4 \%)$ was performed for the control group. Animals were monitored and tumor length and width were measured every other day, and tumor volume was calculated according to the following formula: Length $\mathrm{x}$ width ${ }^{2} / 2$. Measurements were performed in a manner blinded to group allocation. All animals were euthanized by cervical dislocation within 4 weeks after inoculating cancer cells. The animal study was designed and carried out according to the principles of Sun Yat-sen University Institutional Animal Care and Use Committee. Animals were sacrificed due to progressive disease if tumor burden was $>2,500 \mathrm{~mm}^{3}$ according to the Animal Care Guidelines of Sun Yat-sen University Institutional Animal Care and Use Committee. All tumors were $<2,500 \mathrm{~mm}^{3}$ in size. A total of 10 mice were used in each group and no animals died during the experiment until the animals were euthanized by cervical dislocation. Animal health and behavior were monitored every day. Death was verified by observing the animals until no spontaneous breathing was noted for 2-3 min and no blinking reflex was observed. 
Statistical analysis. All experiments were repeated at least three times. The data are presented as the mean \pm standard deviation and were analyzed using SPSS software (v.20.0; IBM Corp.). Differences between two groups were analyzed using an unpaired Student's t-test, and differences among multiple groups were analyzed using one-way ANOVA followed by Tukey's post hoc test. $\mathrm{P}<0.05$ was considered to indicate a statistically significant difference.

\section{Results}

CLC-3 is a target of cell cycle regulators in prostate cancer cells. CLCs have been demonstrated to be key factors in the regulation of the cell cycle and cell proliferation (28). DIDS is a classic CLC blocker (29). The present study first examined whether DIDS affects the rate of cell viability. DU145, PC-3 and HFF-1 cells were treated with various concentrations of DIDS for $48 \mathrm{~h}$, and cell viability was assessed using an MTT assay. Following treatment with DIDS for $48 \mathrm{~h}$, cell viability was suppressed in DU145 and PC-3 cells, but DIDS treatment had no significant effects on HFF-1 cells (Fig. 1A). The results revealed that inhibition of CLCs suppressed cell viability, suggesting that DIDS may suppress cell proliferation. In order to determine whether the decline in viability of DIDS was caused by cell cycle arrest, cell cycle analysis was performed using flow cytometry. DU145 cells were treated with DIDS for 24 and $48 \mathrm{~h}$. DIDS induced $\mathrm{G}_{0} / \mathrm{G}_{1}$ phase arrest compared with cells at $0 \mathrm{~h}$ (Fig. 1B and C). Cyclin D1 is an important regulator of the transition from $G_{0} / G_{1}$ phase to $S$ phase (30). P16, P27 and P53 can bind to cyclin/CDablK (cyclin-dependent kinase) complexes and regulate the $G_{1}-S$ transition by inhibiting the activity of these complexes (31). Western blotting of the cell cycle proteins cyclin D1, P27 and CDK6 demonstrated that DIDS significantly decreased cyclin D1 and CDK6 protein levels, and modestly ( $P>0.05)$ increased P27 protein levels in DU145 cells (Fig. 1D). These data suggest that DIDS blocked cell cycle progression at the $\mathrm{G}_{0} / \mathrm{G}_{1}$ phase, thereby inhibiting DU145 cell proliferation. In order to investigate the role of specific CLC subtypes in regulating the cell cycle in prostate cancer cells, the effects of CLCs on cell cycle progression were evaluated. CLC-3 expression was decreased in DU145 cells following treatment with DIDS (Fig. 1E). To determine the role of endogenous CLC-3 in cell cycle regulation, the effects of CLC-3-knockdown using specific siRNAs on cell cycle progression were determined. The present study screened three siRNA-liposome mixtures via western blotting: siCLC-3-\#1, siCLC-3-\#2 and siCLC-3-\#3. CLC-3 expression levels were most clearly decreased by siCLC-3-\#2 and siCLC-3-\#3 (Fig. 1F). Cell cycle distribution was analyzed via flow cytometry. CLC-3-knockdown inhibited the progression of cells from $G_{1}$ phase to $S$ phase (Fig. $1 G$ and $H$ ). Additionally, western blotting of the cell cycle proteins cyclin D1 and P27 revealed that CLC-3 knockdown significantly decreased cyclin D1 protein expression and increased P27 protein expression in DU145 cells (Fig. 1I). The present study demonstrated that CLC-3 was involved in cell cycle regulation in DU145 cells, and that knockdown of this protein arrested cells at $G_{0} / G_{1}$ phase.

SOX2 arrests DU145 cells at the $G_{0} / G_{I}$ phase. In order to investigate the upstream molecular targets in the effects on cell cycle, DU145 cells were treated with DIDS, and whole genome expression analysis was performed using a gene chip in the present study. It was revealed that SOX2 expression was decreased to the greatest extent (Fig. 2A). Subsequently, western blotting was used to examine the protein expression levels of SOX2 following DIDS treatment. SOX2 expression was markedly decreased in the DIDS treatment group compared with cells at $0 \mathrm{~h}$ (Fig. 2B). In order to verify the role of SOX2 in the regulation of the cell cycle, the effects of knockdown of SOX2 expression with SOX2 siRNA on cell cycle progression were evaluated. To determine the efficiency of the SOX2 siRNA, the present study used western blotting to detect SOX2 protein expression, which was decreased after 48 h of treatment with SOX2-\#1, SOX2-\#2 and SOX2-\#3 siRNA (Fig. 2C). Since SOX2-\#1 did not display a significant interference efficiency, SOX2-\#2 and SOX2-\#3 siRNA were used to decrease SOX2 expression and detect cell cycle changes via flow cytometry. The results indicated that SOX2 siRNA inhibited cell cycle progression by arresting the cells in the $G_{0} / G_{1}$ phase (Fig. 2D and E), which was consistent with the results that occurred after inhibiting CLCs or exposing cells to CLC-3 siRNA. Next, western blot analysis of the cell cycle proteins cyclin D1 and P27 demonstrated that SOX2 knockdown also significantly decreased cyclin D1 protein levels and increased P27 protein levels in DU145 cells (Fig. 2F). Therefore, the present study concluded that SOX2 was involved in the cell cycle changes following inhibition of CLCs. However, the interaction mechanism between SOX2 and CLCs remains unclear.

CLC-3 and SOX2 co-regulate the cell cycle in prostate cancer cells. The results suggested that SOX2 and CLC-3 exhibit the same cell cycle regulatory behavior. The present study assessed whether endogenous SOX2 and CLC-3 interact with each other. Western blot analysis demonstrated the association between SOX2 and CLC-3. Knockdown of endogenous CLC-3 expression decreased SOX2 expression (Fig. 3A). Subsequently, coimmunoprecipitation experiments analyzed the interaction between CLC-3 and SOX2. SOX2 coimmunoprecipitated CLC-3, and CLC-3 coimmunoprecipitated SOX2 (Fig. 3B). Next, to further investigate the association between SOX and CLC-3, the expression of these proteins was knocked down, and the effects were analyzed using immunofluorescence. The fluorescence intensity of CLC-3 and SOX2 was decreased in the siCLC-3 groups compared with the control group (Fig. 3C). The fluorescence intensity of SOX2 and CLC-3 was decreased in the siSOX2 groups compared with in the control group (Fig. 3D). Based on these findings, it was suggested that SOX2 can bind to CLC-3, and that CLC-3 can also individually bind to $\mathrm{SOX} 2$, and co-regulate the cell cycle.

DIDS restricts tumor growth. Given the concerns regarding the DIDS efficacy in vitro, the present study aimed to evaluate this influence in a subcutaneous xenograft model. A DU145 subcutaneous xenograft model was developed in nude mice. The present study performed subcutaneous injections of DIDS. The tumor volume in the DIDS (45 mg/kg) group remained at $\sim 0.4 \mathrm{~cm}^{3}$, but the tumor volume was increased to $0.8 \mathrm{~cm}^{3}$ in the control group (Table $\mathrm{SI}$ ). Tumor growth was markedly restricted in the DIDS group compared with in the control group (Fig. 4A; Table SI). In addition, the present 

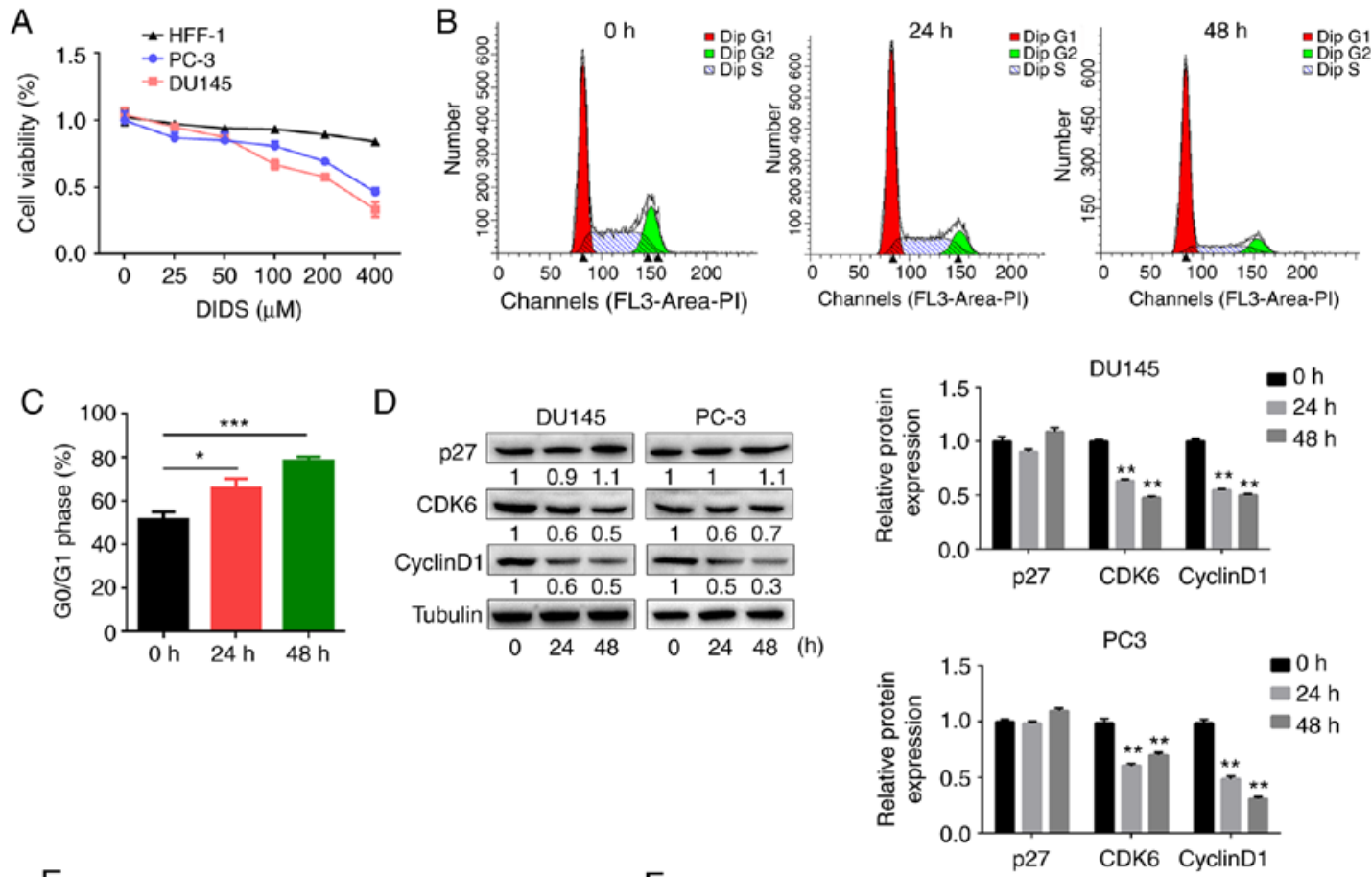

$\mathrm{E}$

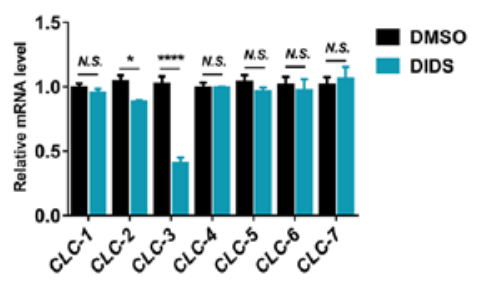

$\mathrm{F}$
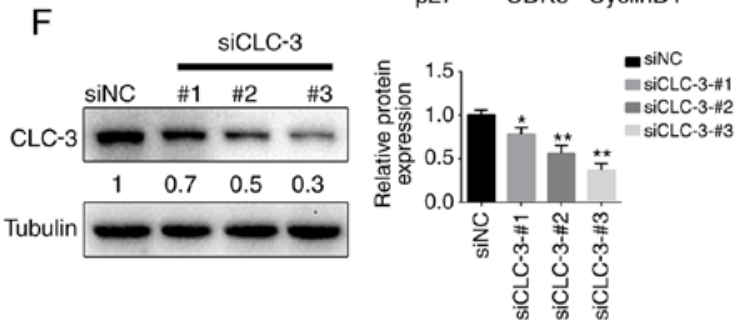
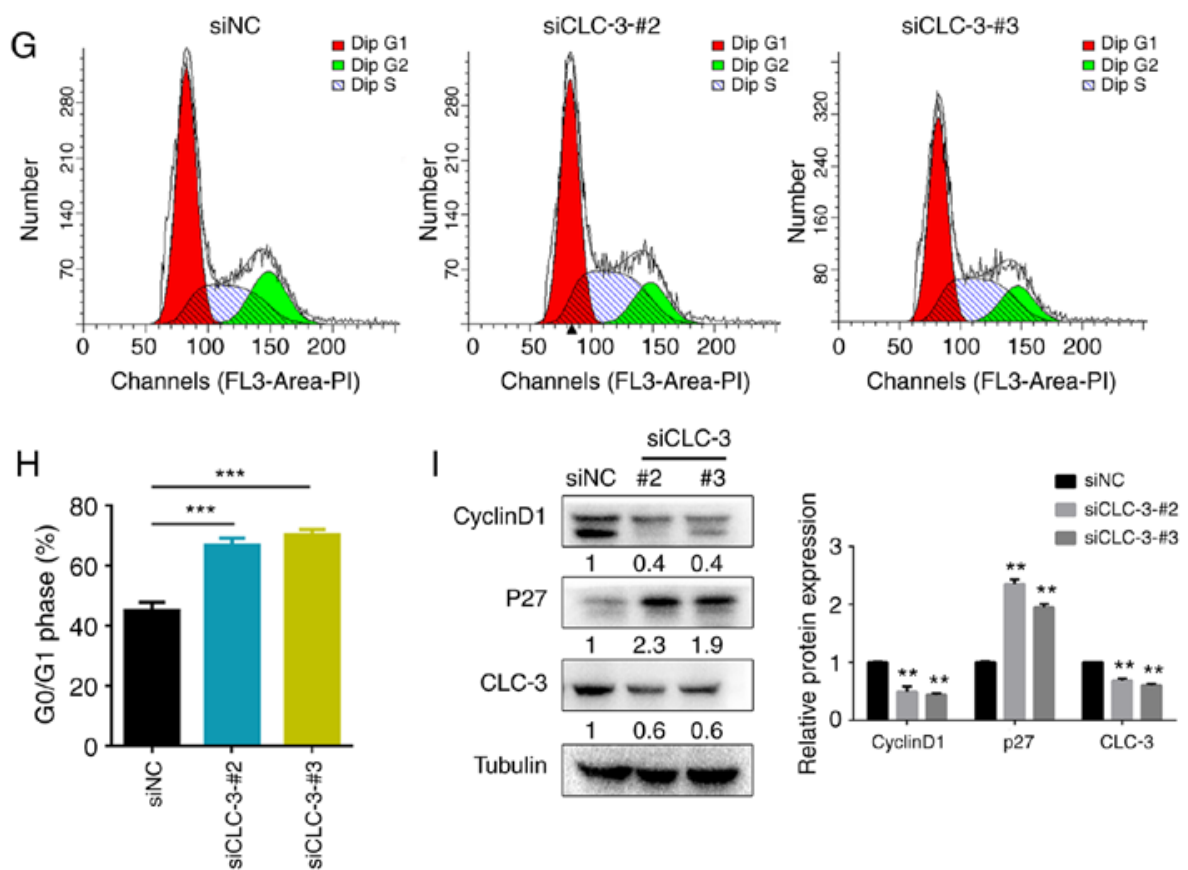

Figure 1. Effects of DIDS in prostate cancer cells. (A) Cell viability of DU145 and PC-3 prostate cancer cells and normal human skin fibroblast HFF-1 cells. Cells were treated with DIDS, and cell viability was determined after $48 \mathrm{~h}$ using an MTT assay. (B and C) Cell cycle distribution of DU145 cells detected by flow cytometry following treatment with $100 \mu \mathrm{M}$ DIDS for 24 and $48 \mathrm{~h}$. Quantitative analysis of cell cycle distribution $(\mathrm{n}=3)$. ${ }^{*} \mathrm{P}<0.05$ and ${ }^{* * * *} \mathrm{P}<0.001$ vs. $0 \mathrm{~h}$. (D) Western blot analysis of cyclin D1, p27 and CDK6 protein expression following treatment with DIDS (100 $\mu \mathrm{M})$ for 24 and $48 \mathrm{~h}$. The numbers under the plots represent the relative quantitative value of the control group after removing the internal reference. ${ }^{* *} \mathrm{P}<0.01 \mathrm{vs} .0 \mathrm{~h}$. (E) RT-qPCR analysis of the expression of chloride channel subtypes in DU145 cells following treatment with DIDS $(100 \mu \mathrm{M})$. mRNA levels were quantified via RT-qPCR. "P<0.05 and ${ }^{* * * * *} \mathrm{P}<0.0001$ vs. DMSO. (F) CLC-3 protein expression in control cells and cells transfected with CLC-3 siRNA (n=3). ${ }^{*} \mathrm{P}<0.05$ and ${ }^{* *} \mathrm{P}<0.01$ vs. siNC. (G) Cell cycle distribution detected by flow cytometry in control cells and in those transfected with CLC-3 siRNA. (H) Quantitative analysis of cell cycle distribution $(\mathrm{n}=3) .{ }^{* * *} \mathrm{P}<0.001$ vs. siNC. (I) Western blot analysis of cyclin D1 and P27 protein expression following transfection with CLC-3 siRNA. ${ }^{* *} \mathrm{P}<0.01$ vs. siNC. Data are presented as the mean \pm SD. CLC-3, chloride voltage-gated channel 3; CLCN, chloride voltage-gated channel; N.S., not significant; RT-qPCR, reverse transcription-quantitative PCR; siNC, negative control (scrambled siRNA); si, small interfering RNA. 

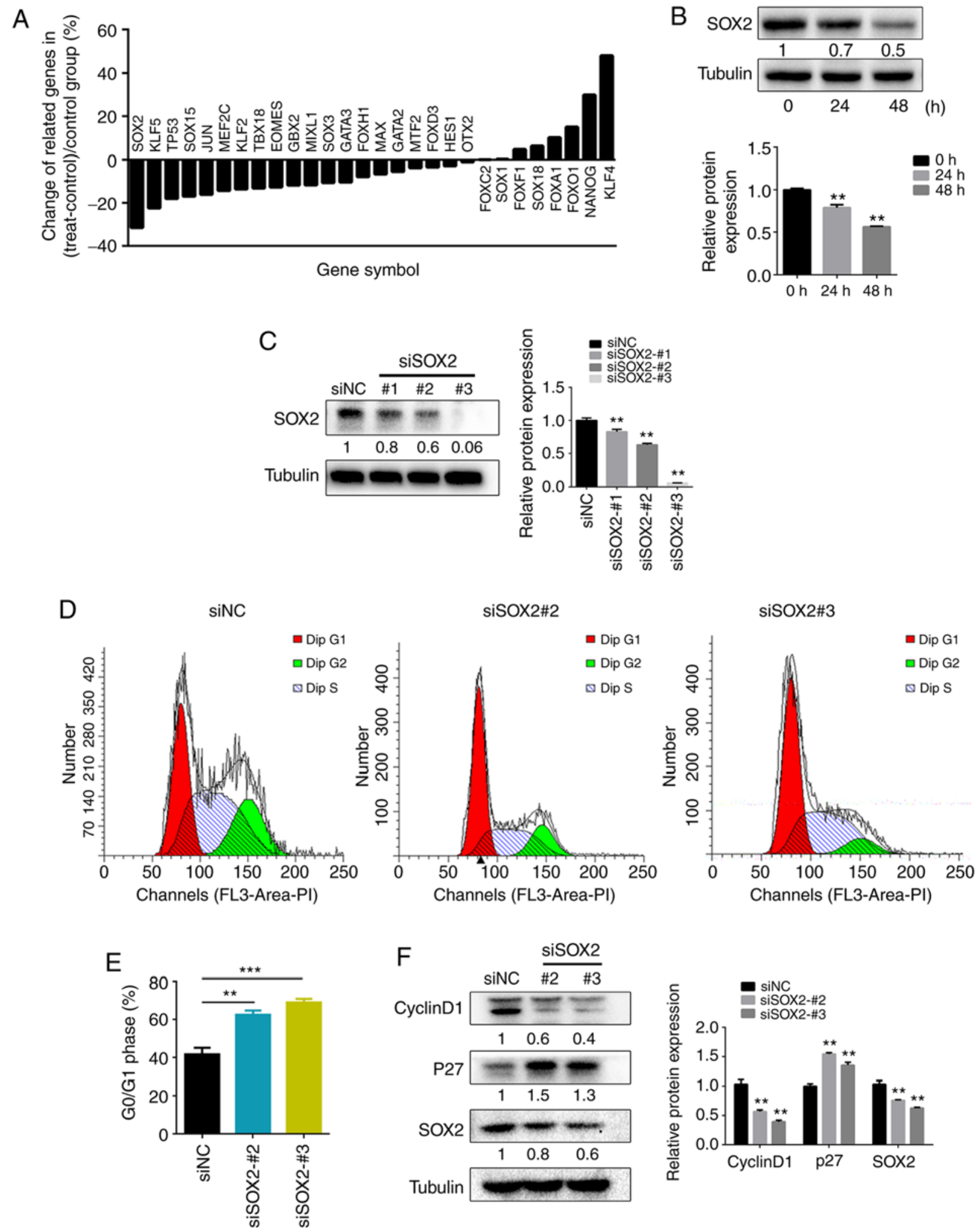

Figure 2. Gene chip screening for key proteins. (A) Gene chip analysis of changes in the stemness gene family. (B) Western blot analysis of SOX2 expression after 24 and $48 \mathrm{~h}$ of treatment with DIDS $(100 \mu \mathrm{M}) .{ }^{* *} \mathrm{P}<0.01 \mathrm{vs} .0 \mathrm{~h}$. (C) SOX2 protein expression in control cells and in cells transfected with SOX2 siRNA. ${ }^{* *} \mathrm{P}<0.01$ vs. siNC. (D) Cell cycle distribution detected by flow cytometry in control cells and those treated with SOX2 siRNA. (E) Quantitative analysis of cell cycle distribution (mean $\pm \mathrm{SD} ; \mathrm{n}=3$ ). ${ }^{* *} \mathrm{P}<0.01$ and ${ }^{* * *} \mathrm{P}<0.001$ vs. siNC. (F) Western blot analysis of cyclin D1 and $\mathrm{P} 27$ protein expression following transfection with SOX2 siRNA. ${ }^{* *} \mathrm{P}<0.01$ vs. siNC. siNC, negative control (scrambled siRNA); siRNA, small interfering RNA; SOX2, sex determining region Y-box 2.

study analyzed CLC-3, SOX2, P27 and cyclin D1 expression in DU145 subcutaneous xenograft tumor sections by immunohistochemistry staining across DIDS groups. Blue staining indicated the nucleus, and brown staining indicated the target protein. In the DIDS group, the expression levels of CLC-3, SOX2 and cyclin D1 were decreased, whereas P27 expression was increased (Fig. 4B). It was suggested that DIDS blocked the tumor cell cycle and inhibited tumor growth in vivo. 
A

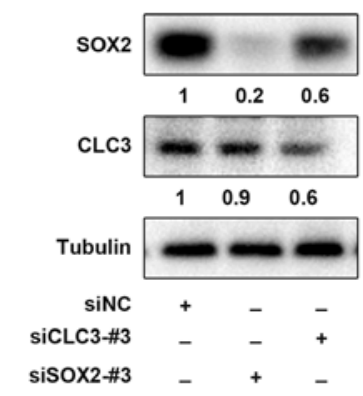

C
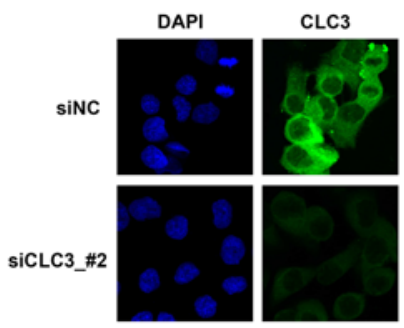

sicLC3_\#3

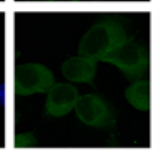

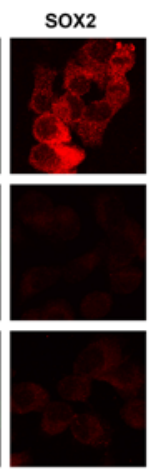

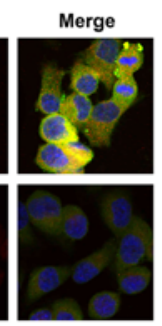

D

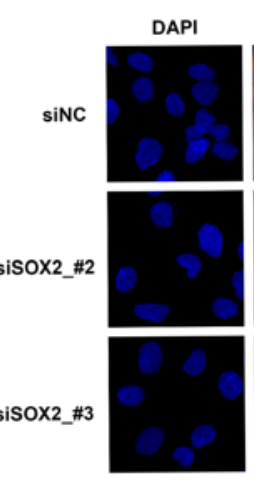

Input: SOX2

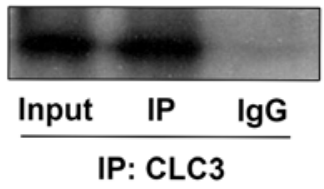

Input: CLC3

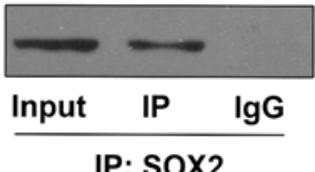

IP: SOX2

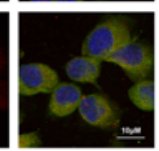

Figure 3. Association between SOX2 and CLC-3. (A) Western blotting demonstrated the association between SOX2 and CLC-3 (mean \pm SD; $\mathrm{n}=3$ ). ${ }^{* *} \mathrm{P}<0.01 \mathrm{vs}$. siNC. (B) SOX2-CLC-3 coimmunoprecipitations in DU145 cells. (C) Immunofluorescence analysis of CLC-3 (green) and SOX2 (red) of siCLC-3 or siNC in DU145 cells. DAPI staining of nuclei was performed. Scale bar, $10 \mu \mathrm{m}$. (D) Immunofluorescence analysis of CLC-3 (green) and SOX2 (red) of siSOX2 or siNC in DU145 cells. DAPI staining of nuclei was performed. Scale bar, $10 \mu \mathrm{m}$. siNC, negative control (scrambled siRNA); siRNA, small interfering RNA; SOX2, sex determining region Y-box 2; CLC-3, chloride voltage-gated channel 3.

A

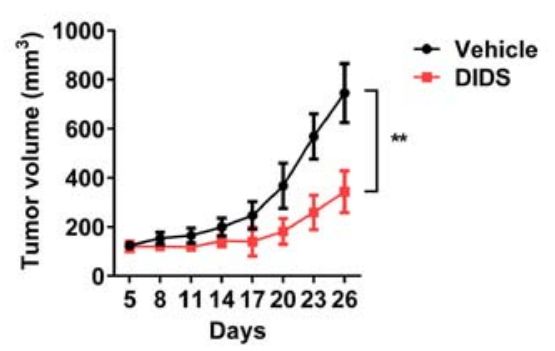

B

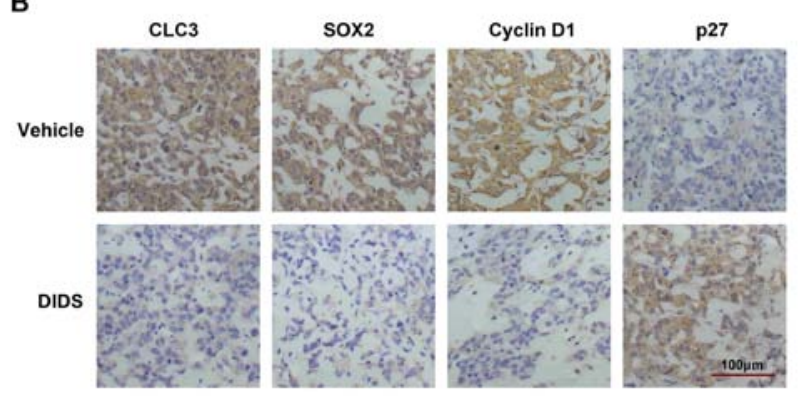

Figure 4. DIDS decreases prostate tumor size. (A) Measurement of the antitumor effects of DIDS in vivo. Nude mice bearing subcutaneous DU145 tumors were treated with DIDS ( $45 \mathrm{mg} / \mathrm{kg} / \mathrm{day})$. Tumor growth was assessed by tumor volume measurement over time (mean $\pm \mathrm{SD} ; \mathrm{n}=10$ ). ${ }^{* *} \mathrm{P}<0.01$ vs. vehicle. Mice were anesthetized and sacrificed at experimental endpoints. Tumors were subsequently dissected. (B) Protein expression in tumor mass assessed by immunohistochemistry. Immunohistochemistry was performed to analyze the expression levels of CLC-3, SOX2, cyclin D1 and P27. Scale bar, $100 \mu \mathrm{m}$. CLC-3, chloride voltage-gated channel 3; SOX2, sex determining region Y-box 2.

\section{Discussion}

Cancer stem cells are a minor fraction of cancer cells but can enable tumor heterogeneity and initiate tumor formation. Accumulating evidence has demonstrated the existence of cancer stem cells and supports their role in conferring therapeutic resistance (32). Malignant tumors are characterized by poor prognosis, increased invasiveness and high recurrence rates. Tumors are difficult to cure due to the development of therapeutic resistance (33). Malignant tumor cells exhibit cancer-like stem cell properties with high expression levels of stemness genes $(34,35)$. The abnormal expression of CLCs is closely associated with the occurrence and development of malignant tumors (36). Studying malignant tumor resistance and CLCs has become popular in international and domestic research (37-39). However, there is little proof regarding the association between CLCs and stemness.

CLCs have various important roles in cellular functions, ranging between control of cell excitability and regulation of cell volume (40). CLC-3 are members of the voltagegated CLC superfamily and are upregulated in numerous cancer cells. PCR demonstrated a marked change in CLC-3 expression compared with other CLC family members following treatment with DIDS in prostate cancer cells. In the plasma membrane, CLC-3 functions as a CLC and is associated with cell proliferation and apoptosis (41). CLC-3 is also located in intracellular compartments, contributing 
to cellular acidity, which increases drug sequestration and leads to chemotherapy drug resistance (20). The present study suggested that CLC-3 serves a role in androgen resistance in DU145 cells. DIDS treatment or transfection with CLC-3 siRNA inhibited cell proliferation by arresting cells in the $\mathrm{G}_{0} / \mathrm{G}_{1}$ phase via the downregulation of cyclin D1 and the upregulation of P27.

Gene chip analysis demonstrated marked changes in stemness-associated factors following DIDS treatment and a significant change in SOX2. Therefore, the present study focused on SOX2. SOX2 is associated with numerous biological processes, including cell cycle, migration, DNA damage and apoptosis, and is essential during mammalian embryogenesis and later in life; however, abnormal SOX2 expression can be pernicious (42). Several previous studies have demonstrated that exogenous elevation of SOX2 levels can promote resistance to clinical treatment (43-45). Notably, reductions in SOX2 levels have been demonstrated to significantly decrease cell viability, clonal growth, sphere formation and tumorigenicity in a number of different types of malignant cancer (46). Stable overexpression of SOX2 has been reported to increase growth in the gastric tumor N87 cell line both in vitro and in vivo (47), while another study has demonstrated that SOX2 regulates the cell cycle proteins cyclin D1 and P27, and that overexpression of SOX2 confers a poor prognosis in terms of malignancy (48). SOX2 can regulate P27 and cyclin D1 to promote the $G_{0} / G_{1}$ phase transition in Ewing's sarcoma, which expresses high levels of SOX2 (49). In the present study, knockdown of SOX2 arrested the cell cycle at the $G_{0} / G_{1}$ phase in DU145 cells. It was suggested that SOX 2 may be a target of CLC-3 as it has the same effect as CLC-3 on cell cycle in DU145 cells. Western blotting and immunoprecipitation assays revealed the association between SOX2 and CLC-3. SOX2 coimmunoprecipitated CLC-3, and conversely, CLC-3 individually coimmunoprecipitated SOX2, indicating that there is bi-directional regulation between SOX2 and CLC-3.

The present study provided novel insights into the treatment of malignant prostate cancer. To the best of our knowledge, the present study was the first to demonstrate that the CLC protein CLC-3 is closely associated with the stemness gene SOX2, and it was suggested that CLCs could be the potential targets of stemness genes. Recognizing and focusing on the role of this association in therapeutic resistance could improve the treatment options for patients with various types of cancer, particularly those with refractory tumors, and it will support the development of novel strategies to more effectively treat some of the deadliest cancers.

\section{Acknowledgements}

Not applicable.

\section{Funding}

The present study was supported by the Science and Technology Planning Project of Guangdong Province (grant no. 2014A020211022), and the Science and Technology Planning Project of Guangzhou Canton (grant no. 201510010074).

\section{Availability of data and materials}

The datasets used and/or analyzed during the current study are available from the corresponding author on reasonable request.

\section{Authors' contributions}

JC, FW and XL were primarily involved in the experimental design. JC and FW wrote the manuscript. JC, FW and $\mathrm{YH}$ reviewed, collected and analyzed the data. YL, SY, XC and $\mathrm{YH}$ performed the experiments. All authors read and approved the final manuscript.

\section{Ethics approval and consent to participate}

All animal experiments were approved by the Sun Yat-sen University Institutional Animal Care and Use Committee and the Animal Ethical and Welfare Committee.

\section{Patient consent for publication}

Not applicable.

\section{Competing interests}

The authors declare that they have no competing interests.

\section{References}

1. Summers N, Vanderpuye-Orgle J, Reinhart M, Gallagher M and Sartor O: Efficacy and safety of post-docetaxel therapies in metastatic castration-resistant prostate cancer: A systematic review of the literature. Curr Med Res Opin 33: 1995-2008, 2017.

2. Best CJ, Gillespie JW, Yi YJ, Chandramouli GV, Perlmutter MA, Gathright Y, Erickson HS, Georgevich L, Tangrea MA, Duray PH, et al: Molecular alterations in primary prostate cancer after androgen ablation therapy. Clin Cancer Res 11: 6823-6834, 2005.

3. Dicitore A, Grassi ES, Borghi MO, Gelmini G, Cantone MC, Gaudenzi G, Persani L, Caraglia M and Vitale G: Antitumor activity of interferon- $\beta 1 \mathrm{a}$ in hormone refractory prostate cancer with neuroendocrine differentiation. J Endocrinol Invest 40: 761-770, 2017.

4. Katzenwadel A and Wolf P: Androgen deprivation of prostate cancer: Leading to a therapeutic dead end. Cancer Lett 367: 12-17, 2015.

5. Boccellino M, Alaia C, Misso G, Cossu AM, Facchini G, Piscitelli R, Quagliuolo L and Caraglia M: Gene interference strategies as a new tool for the treatment of prostate cancer. Endocrine 49: 588-605, 2015.

6. Yao TT: The progress of cancer stem cells in gynecology oncology. J Int Obstetrics Gynecol, 2010.

7. Farhana L, Antaki F, Anees MR, Nangia-Makker P, Judd S, Hadden T, Levi E, Murshed F, Yu Y, Van Buren E, et al: Role of cancer stem cells in racial disparity in colorectal cancer. Cancer Med 5: 1268-1278, 2016.

8. Lin F, Lin P, Zhao D, Chen Y, Xiao L, Qin W, Li D, Chen H, Zhao B, Zou H, et al: Sox 2 targets cyclinE, p27 and survivin to regulate androgen-independent human prostate cancer cell proliferation and apoptosis. Cell Prolif 45: 207-216, 2012.

9. Dean M, Fojo T and Bates S: Tumour stem cells and drug resistance. Nat Rev Cancer 5: 275-284, 2005.

10. Liu Z, Zhang W, Phillips JB, Arora R, McClellan S, Li J, Kim JH, Sobol RW and Tan M: Immunoregulatory protein B7-H3 regulates cancer stem cell enrichment and drug resistance through MVP-mediated MEK activation. Oncogene 38: 88-102, 2019.

11. Najafi M, Farhood B and Mortezaee K: Cancer stem cells (CSCs) in cancer progression and therapy. J Cell Physiol 234: 8381-8395, 2019. 
12. Chen J, Ding P, Li L, Gu H, Zhang X, Zhang L, Wang N, Gan L, Wang Q, Zhang W and Hu W: CD59 regulation by SOX2 Is required for epithelial cancer stem cells to evade complement surveillance. Stem Cell Reports 8: 140-151, 2017.

13. Amini S, Fathi F, Mobalegi J, Sofimajidpour H and Ghadimi T: The expressions of stem cell markers: Oct4, Nanog, Sox2, nucleostemin, Bmi, Zfx, Tcl1, Tbx3, Dppa4, and Esrrb in bladder. colon, and prostate cancer, and certain cancer cell lines. Anat Cell Biol 47: 1-11, 2014

14. Balça-Silva J, Matias D, Dubois LG, Carneiro B, do Carmo A, Girão H, Ferreira F, Ferrer VP, Chimelli L, Filho PN, et al: The expression of connexins and SOX 2 reflects the plasticity of glioma stem-like cells. Transl Oncol 10: 555-569, 2017.

15. Basu-Roy U, Seo E, Ramanathapuram L, Rapp TB, Perry JA, Orkin SH, Mansukhani A and Basilico C: Sox2 maintains self renewal of tumor-initiating cells in osteosarcomas. Oncogene 31 : 2270-2282, 2012.

16. Boumahdi S, Driessens G, Lapouge G, Rorive S, Nassar D, Le Mercier M, Delatte B, Caauwe A, Lenglez S, Nkusi E, et al SOX2 controls tumour initiation and cancer stem-cell functions in squamous-cell carcinoma. Nature 511: 246-250, 2014.

17. Zhao D, Pan C, Sun J, Gilbert C, Drews-Elger K, Azzam DJ, Picon-Ruiz M, Kim M, Ullmer W, El-Ashry D, et al: VEGF drives cancer-initiating stem cells through VEGFR-2/Stat3 signaling to upregulate Myc and Sox2. Oncogene 34: 3107-3119, 2015.

18. Yang S, Zheng J, Xiao X, Xu T, Tang W, Zhu H, Yang L, Zheng S, Dong K, Zhou G and Wang Y: SOX2 promotes tumorigenicity and inhibits the differentiation of I-type neuroblastoma cells. Int J Oncol 46: 317-323, 2015.

19. Matsuoka J, Yashiro M, Sakurai K, Kubo N, Tanaka H, Muguruma K, Sawada T, Ohira M and Hirakawa K: Role of the stemness factors sox 2 , oct $3 / 4$, and nanog in gastric carcinoma. J Surg Res 174: 130-135, 2012.

20. Matsuoka J, Yashiro M, Sakurai K, Kubo N, Tanaka H, Muguruma K, Sawada T, Ohira M and Hirakawa K: Research and progress on ClC2 (Review). Mol Med Rep 16: 11-22, 2017.

21. Abeyrathne PD, Chami M and Stahlberg H: Biochemical and biophysical approaches to study the structure and function of the chloride channel $(\mathrm{ClC})$ family of proteins. Biochimie 128-129: 154-162, 2016.

22. Zhao W, Lu M and Zhang Q: Chloride intracellular channel 1 regulates migration and invasion in gastric cancer by triggering the ROS-mediated p38 MAPK signaling pathway. Mol Med Rep 13: 3711, 2016.

23. Xu B, Mao J, Wang L, Zhu L, Li H, Wang W, Jin X, Zhu J and Chen L: ClC-3 chloride channels are essential for cell proliferation and cell cycle progression in nasopharyngeal carcinoma cells. Acta Biochim Biophys Sin (Shanghai) 42: 370-380, 2010.

24. Li X, Wang T, Zhao Z and Weinman SA: The ClC-3 chloride channel promotes acidification of lysosomes in $\mathrm{CHO}-\mathrm{K} 1$ and Huh-7 cells. Am J Physiol Cell Physiol 282: C1483-C1491, 2002

25. Suh KS, Malik M, Shukla A and Yuspa SH: CLIC4, skin homeostasis and cutaneous cancer: Surprising connections. Mol Carcinog 46: 599-604, 2007.

26. Ponsioen B, van Zeijl L, Langeslag M, Berryman M, Littler D, Jalink K and Moolenaar WH: Spatiotemporal regulation of chloride intracellular channel protein CLIC4 by RhoA. Mol Biol Cell 20: 4664-4672, 2009.

27. Livak KJ and Schmittgen TD: Analysis of relative gene expression data using real-time quantitative PCR and the 2(-Delta Delta C(T)) method. Methods 25: 402-408, 2001.

28. Huang W, Liu M, Zhu L, Liu S, Luo H, Ma L, Wang H, Lu R, Sun X, Chen L and Wang L: Functional expression of chloride channels and their roles in the cell cycle and cell proliferation in highly differentiated nasopharyngeal carcinoma cells. Physiol Rep 2: e12137, 2014

29. Wang GL, Wang XR, Lin MJ, He H, Lan XJ and Guan YY: Deficiency in ClC-3 chloride channels prevents rat aortic smooth muscle cell proliferation. Circ Res 91: E28-E32, 2002.

30. Lee S, Kwon MC, Jang JP, Sohng JK and Jung HJ: The ginsenoside metabolite compound $\mathrm{K}$ inhibits growth, migration and stemness of glioblastoma cells. Int J Oncol 51: 414-424, 2017.
31. Ye D, Luo H, Lai Z, Zou L, Zhu L, Mao J, Jacob T, Ye W, Wang L and Chen L: ClC-3 chloride channel proteins regulate the cell cycle by Up-regulating cyclin D1-CDK4/6 through suppressing p21/p27 expression in nasopharyngeal carcinoma cells. Sci Rep 6: 30276, 2016.

32. Hatano Y, Fukuda S, Hisamatsu K, Hirata A, Hara A and Tomita H: Multifaceted interpretation of colon cancer stem cells. Int J Mol Sci 18: 1446: 2017.

33. Franceschi E, Minichillo S and Brandes AA: Pharmacotherapy of glioblastoma: Established treatments and emerging concepts. CNS Drugs 31: 675-684, 2017.

34. Zhang H, Zhu L, Zuo W, Luo H, Mao J, Ye D, Li Y, Liu S, Wei Y, Ye W, et al: The ClC-3 chloride channel protein is a downstream target of cyclin D1 in nasopharyngeal carcinoma cells. Int J Biochem Cell Biol 45: 672-683, 2013.

35. Tian Y, Guan Y, Jia Y, Meng Q and Yang J: Chloride intracellular channel 1 regulates prostate cancer cell proliferation and migration through the MAPK/ERK pathway. Cancer Biother Radiopharm 29: 339-344, 2014

36. Klumpp L, Sezgin EC, Eckert F and Huber SM: Ion channels in brain metastasis. Int J Mol Sci 17: 1513, 2016.

37. Chen CD, Wang CS, Huang YH, Chien KY, Liang Y, Chen WJ and Lin KH: Overexpression of CLIC1 in human gastric carcinoma and its clinicopathological significance. Proteomics 7: 155-1567, 2007.

38. Stühmer W and Pardo LA: (+) channels as therapeutic targets in oncology. Future Med Chem 2: 745-755, 2010.

39. McCalmont WF, Heady TN, Patterson JR, Lindenmuth MA, Haverstick DM, Gray LS and Macdonald TL: Design, synthesis, and biological evaluation of novel T-Type calcium channel antagonists. Bioorg Med Chem Lett 14: 3691-3695, 2004

40. Hong S, Bi M, Wang L, Kang Z, Ling L and Zhao C: CLC-3 channels in cancer (Review). Oncol Rep 33: 507-514, 2015.

41. Guan YT, Xie Y, Zhou H, Shi HY, Zhu YY, Zhang XL, Luan Y, Shen XM, Chen YP, Xu LJ, et al: Overexpression of chloride channel-3 (ClC-3) is associated with human cervical carcinoma development and prognosis. Cancer Cell Int 19: 8, 2019.

42. Wuebben EL and Rizzino A: The dark side of SOX2: Cancer-a comprehensive overview. Oncotarget 8: 44917-44943, 2017.

43. Bareiss PM, Paczulla A, Wang H, Schairer R, Wiehr S, Kohlhofer U, Rothfuss OC, Fischer A, Perner S, Staebler A, et al: SOX2 expression associates with stem cell state in human ovarian carcinoma. Cancer Res 73: 5544-5555, 2013.

44. Li D, Zhao LN, Zheng XL, Lin P, Lin F, Li Y, Zou HF, Cui RJ, Chen $\mathrm{H}$ and Yu XG: Sox 2 is involved in paclitaxel resistance of the prostate cancer cell line PC-3 via the PI3K/Akt pathway. Mol Med Rep 10: 3169-3176, 2014.

45. Piva M, Domenici G, Iriondo O, Rábano M, Simões BM, Comaills V, Barredo I, López-Ruiz JA, Zabalza I, Kypta R and Vivanco MD: Sox 2 promotes tamoxifen resistance in breast cancer cells. EMBO Mol Med 6: 66-79, 2014

46. Tian Y, Jia X, Wang S, Li Y, Zhao P, Cai D, Zhou Z, Wang J, Luo $\mathrm{Y}$ and Dong M: SOX2 oncogenes amplified and operate to activate AKT signaling in gastric cancer and predict immunotherapy responsiveness. J Cancer Res Clin Oncol 140: 1117-1124, 2014.

47. Szaryńska M, Olejniczak A and Kmieć Z: The role of cancer stem cells in pathogenesis of colorectal cancer. Postepy Hig Med Dosw (Online) 70: 1469-1482, 2016

48. Stivarou T, Cipolleschi MG, D'Amico M, Mannini A, Mini E, Rovida E, Dello Sbarba P, Olivotto M and Marzi I: The complex metabolic network gearing the G1/S transition in leukemic stem cells: Hints to a rational use of antineoplastic agents. Oncotarget 6: 31985-31996, 2015.

49. Yamawaki K, Ishiguro T, Mori Y, Yoshihara K, Suda K, Tamura R, Yamaguchi M, Sekine M, Kashima K, Higuchi M, et al: Sox2-dependent inhibition of p21 is associated with poor prognosis of endometrial cancer. Cancer Sci 108: 632-640, 2017.

This work is licensed under a Creative Commons Attribution-NonCommercial-NoDerivatives 4.0 International (CC BY-NC-ND 4.0) License. 